\title{
АНТИКОРРУПЦИОННАЯ ЭКСПЕРТИЗА ЗАКОНОДАТЕЛЬСТВА ОРГАНАМИ ПРОКУРАТУРЫ КАК СРЕДСТВО ПОВЫШЕНИЯ ЗАКОННОСТИ И ПРАВОПОРЯДКА В СОВРЕМЕННОЙ РОССИИ
}

Статья затрагивает спорные вопросы, касающиеся антикоррупционной экспертизы законодательства, проводимой ее субъектами. Предмет исследования - надзорная экспертиза, которую осуществляют органы прокуратуры в рамках противодействия коррупции. Автор делает акцент на особенностях таких экспертиз и их отличиях от аналогичной экспертизы, которая осуществляется иными субъектами.

Методологический базис исследования - диалектический материализм и общенаучные методы анализа, синтеза и другие. В качестве специальных использованы формально-юридический, сравнительно правовой и другие собственно юридические методы.

На основании полученных выводов автор делает заключение о том, что надзорная антикоррупционная экспертиза, осуществляемая органа- ми прокуратуры, - один из самых результативных видов экспертизы, поскольку она основана на внушительном опыте, наработанном в этой области, и не зависит от органов-разработчиков законодательных актов и регулярности осуществления.

В завершение в статье обосновывается необходимость решения ряда проблем практики проведения антикоррупционной экспертизы органами прокуратуры РФ и независимыми экспертами. Решение этих проблем позволит значительно повысить качество законодательства, а вместе с тем уровень законности и правопорядка в современной России.

Ключевые слова: антикоррупционная экспертиза, законодательство, законность, коррупциогенные фракторы, субъекты антикоррупционной экспертизы.

\section{ANTI-CORRUPTION EXAMINATION OF THE LEGISLATION BY BODIES OF PROSECUTOR'S OFFICE AS A MEANS TO ENHANCE LEGALITY AND LAW ORDER IN MODERN RUSSIA}

The article touches debatable questions of conducting anti-corruption examination of the legislation by subjects of anti-corruption examination. The supervising examination in the sphere of anti-corruption which is carried out by bodies of prosecutor's office serves the subject of the conducted research. The author pays special attention to features of the expertizes on propensity for corruption which are carried out by bodies of prosecutor's office and also the difference from the similar examination which is carried out by other subjects.

Methodological basis of the conducted research is the dialectic materialism and general scientific methods of knowledge based on it: analysis, synthesis and other. However, the preference is given to specifically legal methods: formal legal, comparative legal and other.

Отечественное правоведение до недавнего времени не уделяло особого внимания иссле-
The author concludes that the supervising expertize which is carried out by bodies of prosecutor's office is one of the most productive types of examination due to independence of the bodies of regulations developers on the one hand, and the frequency of conducting anti-corruption examination, as well as the wide experience in this area,.

The need for the solution of a number of problems related to the practice of anti-corruption examination by bodies of prosecutor's office of the Russian Federation and independent experts is proved in article. The solution of these problems will allow to considerably increase the quality of the legislation, as well as the level of legality and law order in modern Russia.

Key words: anti-corruption examination, legislation, legality, factors of propensity for corruption, subjects of anti-corruption examination.

дованию законодательных актов на предмет коррупциогенности, а проработка механизмов 
предупреждения возникновения данной проблемы является относительно новой потребностью, продиктованной реалиями современного правотворчества и правоприменения. Тем не менее, российские ученые в последнее десятилетие стали все больше акцентировать свои научные изыскания на этом вопросе.

Исходя из существующих научных концепций отечественной и зарубежной науки, коррупциогенность законодательства - это дефект одного или целой системы нормативно-правовых актов, допускающий и потенциально порождающий преступления коррупционной направленности [13, р. 1734]. В свою очередь, деятельность экспертов по выявлению, изучению и устранению коррупциогенных фракторов, наличествующих в законодательных документах, следует считать деятельностью по предупреждению коррупциогенности законодательства $[7$, с. 35].

Предупреждение коррупциогенности правовых и законодательных актов - сложный процесс, подразумевающий целостное и системное сочетание многих аспектов, единый в своих различных проявлениях и направлениях и требующий комплексного подхода к рассмотрению и реализации. В связи с этим чрезвычайно важны детальное изучение, классификация и интегративная оценка элементов, его составляющих, основанные на методах системного анализа. Так, например, по основанию целеполагания выделяют общесоциальный (общий) и специальный уровни предупреждения коррупциогенности [8, с. 340]. Сорера общесоциального уровня - государственная и общественная деятельность, а также деятельность государственных и общественных институтов, цель которой - разрешение экономических, социальных, духовно-нравственных и иных противоречий, неизменно возникающих в процессе жизни и деятельности государства и его граждан. Позитивный профилактический эффект наступает в результате проведения грамотной социальной и экономической политики [9, с. 278].

На специальном уровне происходит целенаправленное воздействие на коррупциогенные факторы отдельных коррупциогенных законодательных видов и групп. В целом специальный уровень можно представить в виде системы: объекты и субъекты воздействия, а также его приемы и методы.

Необходимо отметить, что эффрективность профилактики коррупциогенности законодательства напрямую зависит от верного выбора уровня ее осуществления - соответственно, общесоциального или собственно-юридиче- ского. Собственно-юридический уровень предотвращения коррупциогенности также может быть представлен как система объектов предотвращения, субъектов, осуществляющих антикоррупциогенную деятельность, и приемов и методов предупредительного воздействия.

Субъекты предупреждения коррупциогенности российского законодательства условно можно поделить на субъекты общесоциальной профилактики и субъекты специально-юридической профилактики.

Субъекты общесоциальной профилактики это органы власти федерального (Президент, Федеральное Собрание РФ, Правительство и др.) и регионального уровней и другие субъекты, не наделенные компетенцией на непосредственное осуществление функций правоохранения [16, с. 105].

Субъекты специально-юридической профилактики - это обширный круг субъектов, осуществляющих антикоррупционную экспертизу законодательных и нормативно-правовых актов. Данный вид экспертизы служит правореализационным механизмом, направленным на недопущение наличия в них коррупциогенных факторов, порождающих различные коррупционные правонарушения [17].

Выделяют внутреннюю, внешнюю и независимую антикоррупционную экспертизу. Внутренняя экспертиза законодательных актов проводится органами и должностными лицами, в компетенции которых принятие или издание этих актов. Проведение внешней антикоррупционной экспертизы находится в ведении правоохранительных органов - прокуратуры и юстиции. Суть независимой экспертизы в целом совпадает с сутью экспертизы внешней, но поскольку независимая экспертиза проводится негосударственными гражданскими объединениями или отдельными гражданами, целесообразно будет назвать ее общественной экспертизой [14, p. 8].

Исходя из части 1 статьи 3 Ф3 № 172 от 17.07.2009 (ред. от 21.10.2013), известно, что антикоррупционная экспертиза законодательных актов и их проектов осуществляется следующими субъектами: органами прокуратуры Российской Федерации; Министерством юстиции РФ; органами, организациями и должностными лицами, издающими и принимающими нормативно-правовые акты и их проекты, на стадии проведения правовой экспертизы законопроектов и мониторинга их применения и действия [1]. Если в нормативно-правовых актах и их проектах обнаруживаются фракторы коррупциогенности, и их устранение требует 
принятия мер, которые не входят в компетенцию означенного круга субъектов, то об этом информируются органы прокуратуры.

Деятельность органов Минюста РФ по предупреждению коррупциогенности законодательства регламентируется следующими документами фредерального значения: Федеральным законом № 273-Ф3 (ред. от 28.12.2017) «О противодействии коррупции» от 25 декабря 2008 года; Федеральным законом № 172-Ф3 (ред. от 21.10.2013) «Об антикоррупционной экспертизе нормативных правовых актов и проектов нормативных правовых актов» от 17 июля 2009 года; постановлением Правительства РФ № 96 (ред. от 10.07.2017) «Об антикоррупционной экспертизе нормативных правовых актов и проектов нормативных правовых актов» от 26 фревраля 2010 года; приказом Минюста РФ № 77 (ред. от 30.09.2015) «Об организации работы по проведению антикоррупционной экспертизы нормативных правовых актов субъектов Российской Федерации и уставов муниципальных образований» от 01 апреля 2010 года и другими законодательными актами.

Превентивная антикоррупционная деятельность органов госвласти, самоуправления и прокуратуры Российской Федерации регламентируется рядом законодательных документов, таких, как Федеральный закон № 172-Ф3 (ред. от 21.10.2013) «Об антикоррупционной экспертизе нормативных правовых актов и проектов нормативных правовых актов», принятый 17 июля 2009 года, приказов Генерального прокурора Российской Федерации года № 400 (ред. от 13.03.2018) «Об организации проведения антикоррупционной экспертизы нормативных правовых актов» от 28 декабря 2009 и № 209 (ред. от 09.02.2012) «Об усилении прокурорского надзора в свете реализации Национальной стратегии противодействия коррупции», датированным 15 мая 2010 года.

В статье 9.1 Ф3 № 2202-1 (ред. 18.04.2018) «О прокуратуре Российской Федерации» от 17 января 1992 года сказано, прокурор проводит антикоррупционную экспертизу нормативно-правовых актов органов исполнительной власти федерального и регионального уровня, органов местного самоуправления в соответствии со своими полномочиями и порядком, установленным Генеральной прокуратурой, и методикой, определенной и утвержденной Правительством РФ [2]. При обнаружении фракторов коррупциогенности в исследуемых нормативно-правовых актах прокурор направляет субъектам, эти акты издавшие, требование об изменении документа, содержащее указание потенциального способа устранения выявленных коррупциогенных факторов. Имеется также и радикальный путь решения проблемы посредством обращения в суд в предусмотренном процессуальным законодательством Российской Федерации порядке. Необходимо отметить, что до рассмотрения требования соответствующим органом, организацией или лицом прокурор полномочен отозвать его.

На сегодняшний день проведение антикоррупционной экспертизы органами прокуратуры осложняется рядом практических проблем, заметно снижающих ее эффективность.

Во-первых, механизм применения прокурорского требования об устранении коррупциогенных факторов в законодательно-правовом акте, закрепленный в статье 9.1 Закона о прокуратуре, дублирует изложенное в статье 23 данного закона предписание о порядке прокурорского опротестования незаконного правового акта. При этом Федеральный закон «О прокуратуре Российской Федерации» однозначно не определяет, является ли антикоррупционная экспертиза законодательных актов частью надзорной функции прокуратуры [12, с. 87]. В связи с этим необходимо четко определить характер нового направления прокурорской деятельности в плане причисления его к разновидностям реализации надзорной функции органов прокуратуры, и, как следствие, исключить положения частей 2 и 3 статьи 9.1 данного закона, перенеся их к главе 1 в виде отдельной, дополнительной статьи 23.1 «Требование прокурора» [4, с. 256].

Во-вторых, на данный период времени острые дискуссии вызывает критерий обязательности исполнения требования прокурора об устранении факторов коррупциогенности нормативно-правового акта

Некоторые исследователи, такие, как, например, Е. Р. Ергашев, отмечают, что статус прокурорских требований таков: они обязательны для рассмотрения, но необязательны для исполнения [5, с. 40]. В связи с этим прокурору обязательно в семидневный срок отправляется лишь отчет о рассмотрении вышеозначенного требования, а не отчет о его исполнении. Данному утверждению противоречит положение, зафиксированное в п. 1 ст. 6 Закона о прокуратуре, из которого следует, что в соответствии с полномочиями прокурора, определенными статьями 9.1, 22, 27, 30 и 33 этого закона, прокурорские требования должны быть исполнены обязательно и в строго установленный срок. Предсказуемые последствия подобного толкования нормы закона - 
его неисполнение и снижение авторитета прокуратуры.

В-третьих, необходимо дополнить Закон о прокуратуре положениями о судебной ответственности за неисполнение прокурорского протеста или требования [10, с. 25].

В-четвертых, требования об устранении коррупциогенных фракторов нормативно-правовых актов, обнаруженных прокурором в ходе проведения антикоррупциогенной экспертизы, направленные в законодательный орган, эти нормативно-правовые акты издавший или применивший, в соответствии с ч. 3 ст. 9.1 и ч. 2 ст. 23 Закона о прокуратуре подлежат обязательному рассмотрению на ближайшем заседании этого органа. На деле же эти заседания зачастую намеренно откладываются на длительный или неопределенный срок, в течение которого нормативно-правовой акт, в котором были обнаружены коррупциогенные фракторы, является действующим и провоцирует коррупционные проявления со стороны должностных лиц. Для того чтобы исключить подобную возможность, предлагается предоставить прокурору право на внеочередной созыв заседания законодательного органа для рассмотрения прокурорского требования и недопущения действия коррупциогенного нормативно-правового акта [3, с. 19].

В-пятых, своим участием в рассмотрении требования прокурор разъясняет возможные негативные правовые последствия, которые возникают в случае применения коррупциогенного закона или нормативно-правового акта, чем обосновывает позицию соответствующего органа надзора. При этом законы «Об антикоррупционной экспертизе нормативных правовых актов и проектов нормативных правовых актов» и «О прокуратуре» не предписывают обязательного участия представителя прокуратуры непосредственно в самом процессе рассмотрения требования. Тем не менее, п. 1.6 Генерального прокурора РФ № 400 требует от руководителей органов прокуратуры обеспечить участие их представителей в рассмотрении требований, направленных в органы госвласти и самоуправления. Исключение составляют только представительные органы власти.

Вышеупомянутый приказ содержит утвержденную форму требования прокурора об устранении из законодательного акта (или его проекта) фракторов, порождающих коррупцию: эта форма включает в себя положения, обосновывающие необходимость, сроки, порядок рассмотрения требования, а также предписывающие заблаговременно информировать представи- теля органов прокуратуры о месте и времени проведения рассмотрения. Однако отсутствие предусмотренной законом ответственности за невыполнение этих предписаний приводит к тому, что в случае, если представитель прокуратуры не ставится в известность о времени и месте рассмотрения, никакие меры взыскания ни к кому не применяются, что в корне неверно и не противоречит концепции правового государства. В связи с этим требуется внести в Закон об антикоррупционной экспертизе дополнение, обязывающее законодательные органы в течение строго регламентированного срока направлять принятые нормативно-правовые акты и их проекты в прокуратуру [11, с. 87].

Деятельность независимых экспертов регулируется ст. 5 Федерального закона № 172-Ф3 «Об антикоррупционной экспертизе нормативных правовых актов и проектов нормативных правовых актов» от 17 июля 2009 года. Исходя из нее, граждане и гражданские общественный институты могут за свой счет проводить независимую экспертизу нормативно-правовых актов и их проектов на предмет наличия коррупциогенных фракторов и выносить по результатам экспертизы заключение, в котором должны быть указаны эти факторы и предложены способы их устранения. Данное заключение носит рекомендательный характер, но при этом оно в тридцатидневный срок с момента получения обязательно должно быть рассмотрено адресатом, и если независимый эксперт не внес никаких предложений по устранению выявленных фракторов коррупциогенности, ему отправляется развернутый ответ, содержащий все необходимые мотивировки и обоснования.

В п. 4 Правил проведения антикоррупционной экспертизы нормативных правовых актов и проектов нормативных правовых актов, утвержденных Постановлением Правительства РФ от 26.02.2010 г. № 96 «Об антикоррупционной экспертизе нормативных правовых актов и проектов нормативных правовых актов» сказано, что проводить независимую антикоррупционную экспертизу имеют право физические и юридические лица, аккредитованные Министерством юстиции Российской Федерации как независимые эксперты.

Деятельность эксперта осложняют следующие проблемы:

- понятия «независимая экспертиза» и «независимый эксперт» законодательно не определены;

- действующая методика лишь перечисляет коррупциогенные факторы, но не регламентирует механизм и порядок проведения антикоррупционной экспертизы; 
- большое количество ведомственных нормативных правовых актов повторяют уже имеющийся и установленный Правительством Российской Федерации порядок проведения экспертизы правовых актов на предмет коррупциогенности;

- нет строго закрепленных сроков, отведенных на проведение экспертизы;

- механизм отбора законодательных актов для экспертизы не закреплен законом;

- статус независимых экспертов не определен на правовом уровне, как не определены статус и роль их заключений в дальнейшей судьбе проверяемых нормативно-правовых актов;

- отсутствуют оценочные критерии результатов независимой экспертизы, не описан порядок действий при определении преимущества одного вида экспертизы перед другим, либо интеграции результатов этих экспертиз (обязательной и независимой);

- должностные лица не несут никакой ответственности за невыполнение предписаний, вынесенных по результатам проведения независимой экспертизы [6].

Решение вышеуказанных проблем существенно повысит эффективность противодействия коррупции и выявления потенциальной коррупциогенности нормативно-правового акта не только на стадии его действия, но даже на стадии разработки. Кроме того, это значительно ускорит принятие мер в случае, если акт уже применяется, и имеют место случаи коррупции в результате его действия.
Итак, на основании вышеизложенного можно сделать следующие выводы.

Во-первых, предупреждение и предотвращение коррупциогенности правовых и законодательных актов - сложный процесс, подразумевающий целостное и системное сочетание многих аспектов, единый в своих различных проявлениях и направлениях и требующий комплексного подхода к рассмотрению и реализации.

Во-вторых, предотвращение и предупреждение коррупциогенности нормативных и правовых актов осуществляется путем уровневого подхода, и то, насколько эффективными будут принятые антикоррупционные меры, зависит от правильности выбранного уровня воздействия. Так, на общесоциальном уровне профилактика коррупциогенности проводится по целому ряду направлений, таких, как организационно-правовое, общекультурное, политическое, экономическое и другие. На собственно-юридическом уровне антикоррупциогенная деятельность осуществляется системно и включает в себя приемы, методы, объекты и субъекты профилактики и воздействия.

В-третьих, в настоящей статье рассмотрен ряд проблем практики проведения органами прокуратуры РФ и независимыми экспертами антикоррупционной экспертизы. Решение этих проблем позволит значительно повысить уровень законодательства, а вместе с тем законность и правопорядок в современной России.

\section{Литература}

1. Федеральный закон от 17.07.2009 № 172-Ф3 (ред. от 21.10.2013) «Об антикоррупционной экспертизе нормативных правовых актов и проектов нормативных правовых актов». URL: http://www.consultant.ru/document/cons_doc_ LAW_89553/ (Дата обращения: 15.05.2018).

2. Федеральный закон от 17.01.1992 № 2202-1 (ред. от 18.04.2018) «О прокуратуре Российской Федерации». URL: http://www.consultant.ru/document/cons_doc_LAW_262/ (Дата обращения: 15.05.2018).

3. Бадмацыренова Ю. С. Проблемы реализации полномочий органов прокуратуры при проведении антикоррупционной экспертизы // Экспертиза нормативных правовых актов и их проектов на предмет коррупциогенности: содержание, значение, методика проведения: сб. статей. М.: [б.и.], 2010. С. 19.

4. Винокуров А. Ю. Требование в системе правовых средств прокурорского надзора // Экспертиза нормативных правовых актов и их проектов на предмет коррупциогенности: содержание, значение, методика проведения. М.: [б.и.], 2010. C. 256

5. Ергашев Е. Р. Принципы института надзора за исполнением законов // Исполнительное право. 2006. №3. С. 40-46.

6. Каменская Е. В., Рождествина А. А. Независимая антикоррупционная экспертиза: научно-практическое пособие URL: http://www.consultant.ru/edu/student/download_books/book/kamenskaia_ev_rozhdestvina_aa_nezavisimaja_ antikorrupcionnaja_ekspertiza/ (Дата обращения: 29.05.2018).

7. Клюковская И. Н. Правовая природа и принципы криминологической антикоррупционной экспертизы нормативных правовых актов // Общество и право. 2011. №5. С. 35-36.

8. Криминология / под ред. В. Н. Кудрявцева и В. Е. Эминова. М.: Юрист, 1999. 512 с.

9. Криминология: учебник для вузов / под общ. ред. д-ра юрид. наук, проф. А. И. Долговой. М.: Изд-во НОРМА (Издательская группа НОРМА- ИНФРА-М), 2001. 784 с.

10. Кудашкин А. В. Проблемы организации и проведения органами прокуратуры антикоррупционной экспертизы // Журнал российского права. 2011. №2. С. 25.

11. Кудашкин А. В., Дмитриев Д. А. К вопросу о необходимости совершенствования правового регулирования проведения органами прокуратуры антикоррупционной экспертизы в целях повышения ее эффективности // Административное и муниципальное право. 2011. №4. С. 87. 
12. Кудашкин А. В., Дмитриев Д. А. К вопросу о необходимости совершенствования правового регулирования проведения органами прокуратуры антикоррупционной экспертизы в целях повышения ее эффективности // Административное и муниципальное право. 2011. №4. С. 95.

13. Klyukovskaya I. N., Galstyan I. S., Lauta O. N., Mayboroda E. T., Cherkashin E. Y. International organizations on fighting against corruption: legal means and methods of their implementation in national legal systems // Journal of Advanced Research in Law and Economics. 2016. Vol. 7. №7. C. 1734

14. Navasardova E. S., Klyukovskaya I. N., Galstyan I. S., Kolesnikova K. V., Nutrikhin R. V. Some of the corruptogenic factors of environmental legislation in the Russian Federation // International Journal of Economics and Financial Issues. 2015. T. 5. №3. P. 8-14.

15. Родионова О. Н. Антикоррупционная экспертиза // Российский юридический журнал. 2010. №1. С. 158.

16. Таможник Е. Л. Преступления против законной деятельности представителей власти: уголовно-правовой и криминологический аспекты: дис. ... канд. юрид. наук. Тамбов, 2006. 296 с.

17. Чаплыгина А. Ю. Правовые основы проведения антикоррупционной экспертизы органами прокуратуры //Государственная власть и местное самоуправление. 2015. №1. URL: http://отрасли-права.pф/article/4863 (Дата обращения: 29.05.2018).

\section{References}

1. Federal'nyj zakon ot 17.07.2009 № 172-FZ (red. ot 21.10.2013) «Ob antikorrupcionnoj ehkspertize normativnyh pravovyh aktov i proektov normativnyh pravovyh aktov" ("On anti-corruption expertise of normative legal acts and draft normative legal acts"). URL: http://www.consultant.ru/document/cons doc LAW 89553/ (Accessed: 15.05.2018). (In Russian).

2. Federal'nyj zakon ot 17.01.1992 № 2202-1 (red. ot 18.04.2018) «O prokurature Rossijskoj Federacii» (“On Prosecutor's office of the Russian Federation"). URL: http://www.consultant.ru/document/cons doc LAW 262/ (Accessed: 15.05.2018). (In Russian).

3. Badmacyrenova Yu. S. Problemy realizacii polnomochij organov prokuratury pri provedenii antikorrupcionnoj ehkspertizy (Problems of implementing the powers of bodies of Prosecutor's office at carrying out anti-corruption examination) /I EHkspertiza normativnyh pravovyh aktov $i$ ih proektov na predmet korrupciogennosti: soderzhanie, znachenie, metodika provedeniya: sb. statej. Moscow, 2010. P. 19. (In Russian).

4. Vinokurov A. Yu. Trebovanie $v$ sisteme pravovyh sredstv prokurorskogo nadzora (Requirement in the system of legal means of prosecutorial supervision) // EHkspertiza normativnyh pravovyh aktov $\mathrm{i}$ ih proektov na predmet korrupciogennosti: soderzhanie, znachenie, metodika provedeniya. Moscow, 2010. P. 256. (In Russian).

5. Ergashev E. R. Principy instituta nadzora za ispolneniem zakonov (Principles of the Institute of supervision of law enforcement) // Ispolnitel'noe pravo. 2006. No.3. P. 40-46. (In Russian).

6. Kamenskaya E. V., Rozhdestvina A. A. Nezavisimaya antikorrupcionnaya ehkspertiza: nauchno-prakticheskoe posobie (Independent anti-corruption expertise: a scientific and practical guide) URL: http://www.consultant.ru/edu/student/download books/book/kamenskaia_ev_rozhdestvina_aa_nezavisimaja_antikorrupcionnaja_ekspertiza/ (Accessed: 29.05.2018). (In Russian).

7. Klyukovskaya I. N. Pravovaya priroda i principy kriminologicheskoj antikorrupcionnoj ehkspertizy normativnyh pravovyh aktov (Legal nature and principles of criminological anti-corruption expertise of normative legal acts) // Obshchestvo i pravo. 2011. No. 5. P. 35-36. (In Russian).

8. Kriminologiya (Criminology) / ed. by V. N. Kudryavcev and V. E. EHminov. Moscow, 1999. 512 p. (In Russian).

9. Kriminologiya (Criminology): uchebnik dlya vuzov / ed by A. I. Dolgova. Moscow: NORMA (Izdatel'skaya gruppa NORMA-INFRA-M), 2001. 784 p. (In Russian).

10. Kudashkin A. V. Problemy organizacii i provedeniya organami prokuratury antikorrupcionnoj ehkspertizy (Problems of organization and carrying out of anti-corruption examination by bodies of Prosecutor's office) // ZHurnal rossijskogo prava. 2011. No.2. P. 25. (In Russian).

11. Kudashkin A. V., Dmitriev D. A. K voprosu o neobhodimosti sovershenstvovaniya pravovogo regulirovaniya provedeniya organami prokuratury antikorrupcionnoj ehkspertizy $\vee$ celyah povysheniya ee ehffektivnosti (On the need to improve the legal regulation of the Prosecutor's office of anti-corruption expertise in order to improve its efficiency) // Administrativnoe i municipal'noe pravo. 2011. No. 4. P. 87. (In Russian).

12. Kudashkin A. V., Dmitriev D. A. K voprosu o neobhodimosti sovershenstvovaniya pravovogo regulirovaniya provedeniya organami prokuratury antikorrupcionnoj ehkspertizy $\vee$ celyah povysheniya ee ehffektivnosti (On the need to improve the legal regulation of the Prosecutor's office of anti-corruption expertise in order to improve its efficiency) // Administrativnoe municipal'noe pravo. 2011. No. 4. P. 95. (In Russian).

13. Klyukovskaya I. N., Galstyan I. S., Lauta O. N., Mayboroda E. T., Cherkashin E. Y. International organizations on fighting against corruption: legal means and methods of their implementation in national legal systems // Journal of Advanced Research in Law and Economics. 2016. Vol. 7. No. 7. P. 1734. (In Russian).

14. Navasardova E. S., Klyukovskaya I. N., Galstyan I. S., Kolesnikova K. V., Nutrikhin R. V. Some of the corruptogenic factors of environmental legislation in the Russian Federation // International Journal of Economics and Financial Issues. 2015. Vol. 5. No. 3. P. 8-14. (In Russian).

15. Rodionova O. N. Antikorrupcionnaya ehkspertiza (Anticorruption examination) // Rossijskij yuridicheskij zhurnal. 2010. No. 1. P. 158. (In Russian).

16. Tamozhnik E. L. Prestupleniya protiv zakonnoj deyatel'nosti predstavitelej vlasti: ugolovno-pravovoj i kriminologicheskij aspekty (Crimes against the legal activities of the authorities: criminal law and criminological aspects). Tambov, 2006. 296 p. (In Russian).

17. Chaplygina A. Yu. Pravovye osnovy provedeniya antikorrupcionnoj ehkspertizy organami prokuratury (Legal basis of anti-corruption expertise by the Prosecutor's office) // Gosudarstvennaya vlast' i mestnoe samoupravlenie. 2015. No.1. URL: http://otrasli-prava.rf/article/4863 (Accessed: 29.05.2018). (In Russian). 